\title{
Innovations in an institutionalised higher education system: the role of embedded agency
}

\author{
Jinyuan $\mathrm{Ma}^{1}$ (D) $\cdot$ Yuzhuo $\mathrm{Cai}^{2} \mathbb{D}$
}

Accepted: 7 January 2021 / Published online: 15 January 2021

(c) The Author(s) 2021

\begin{abstract}
This paper explores how a novel university governance model at Southern University of Science and Technology (SUSTech), largely learned from the West, has been implemented in the highly institutionalised and centralised Chinese higher education system. For this purpose, we first constructed an analytical framework, integrating the conceptualisation of an innovation process in higher education and the concept of embedded agency. This framework was then applied to analyse eight interviews, seven policy documents and six news media reports in our empirical investigation of the case university. Our major research findings are: the governance model adopted by SUSTech was a disruptive innovation and it was mostly challenged by the incompatibility between the norms around the governance model and the institutional context of Chinese higher education; this challenge was mitigated through three agency strategies, labelled by the metaphors of new wine in a new bottle, new wine in an old bottle and old wine in a new bottle. Successfully implementing these strategies calls on the visions, skills of playing power games and social capital of those initiating the innovation. Finally, we discuss the theoretical contribution and practical implications of the study in the conclusion.
\end{abstract}

Keywords University reform · Governance · Innovation · Institutional theory · Institutional entrepreneur · China

\section{Introduction}

Since the 1990s, there has been an increasing volume of literature exploring various higher education innovations in different geographical contexts (Cai, 2017). China, which has the largest higher education system, is no exception. In the past three decades, Chinese higher education has undergone the most profound reforms. China's unique path to the modernisation of higher education (Yan \& Cai, 2019) arguably represents the most complicated in the world, due to China's complex institutional environment in social, economic and political

Yuzhuo Cai

yuzhuo.cai@tuni.fi

1 Center for Higher Education Research, Southern University of Science and Technology, 518055 Shenzhen, China

2 Faculty of Management and Business, Tampere University, 33014 Tampere, Finland 
dimensions (Mok \& Han, 2017). China originally adopted the Soviet Union's model of higher education in the 1950s, but it has transformed to catch up to Western countries using Western means (Hayhoe, 1996). As Yang (2017) explained, "[t]he establishment of modern universities in China has been based on Western values on the one hand, and a system supported by traditional culture on the other" (p. 1826-1827). When ideas related to market mechanisms and decentralisation learned from the West meet the Chinese reality characterised by hierarchy and centralisation (Xu, 2005), it is a large challenge for Chinese higher education to reconcile different ideologies or value systems (Cai \& Yan, 2020).

The Chinese way of tackling the challenges in higher education is not very different from the old reform approach of zhong ti xi yong (preserving the Chinese essence while applying Western means) adopted during the Westernisation Movement in the late Qing Dynasty in the nineteenth century (Cai, 2012). Specifically, the Chinese government uses the term higher education with Chinese characteristics to legitimise the ideological paradoxes in Chinese higher education reforms. Although considered by the government to be a part of the Theory of Socialism with Chinese Characteristics, this notion does not help much in guiding higher education practices because of its ambiguity. As Zhu and Li (2018, p. 1148) have argued, "[t]here is still no clear and accurate definition or illustration that identifies the core ideas of higher education with Chinese characteristics that would enable any distinction between 'higher education with Chinese characteristics' and modern higher education in the West." Higher education with Chinese characteristics can be generally understood as a hybrid system consisting of Western ideas of higher education with the imprints of Chinese culture and tight political control (Li \& Zhu, 2019). This corroborates Zha et al.'s (2016) observation that the Chinese model of higher education is a mix of "Western and Chinese (mainly Confucian) elements" (p. 273) as well as strong state control.

These conflicting value systems in Chinese higher education have a direct impact on the reforms and practices of universities. For instance, in defining his concept of "Chinese University 3.0," Li (2019) describes contemporary Chinese universities as "a uniquely inclusive model which bases itself on the Chinese cultural tradition and is incorporated with applications of Western models" (p. 3). This model entails a paradox, as the fundamental norms and models in Western universities, such as academic freedom and institutional autonomy, are contradictory to the Chinese Confucian tradition (Zha \& Shen, 2018). Chinese universities' efforts to enhance institutional autonomy and academic freedom have been further hindered by strong political control (Du, 2019; Jiang \& Mok, 2019). Yang et al., (2007) used the metaphor "dancing in a cage" to illustrate the paradox of policy discourses on increasing university autonomy in China: while policy dictated that universities were supposed to be more independent of the government, their actual autonomy was limited due to increased accountability imposed by the government. Twelve years later, Han \& $\mathrm{Xu}$ (2019) made a similar observation: "despite the increasing university autonomy and academic freedom in some areas, the state has never abdicated the essential power and authority over higher education institutions" (p. 931).

These studies imply that Chinese universities can hardly be innovative, especially in learning from Western experience, due to the "cage"-a highly institutionalised structure. It remains a puzzle how Chinese universities can escape from bondage. There is a lack of studies on how to resolve such a puzzle because of the lack of both an appropriate example of disruptive innovations in Chinese higher education as well as suitable analytical tools to theoretically conceptualise innovations in a highly institutionalised higher education system. Our paper tries to bridge the research gaps by constructing an analytical framework, integrating the conceptualisation of an innovation process in higher education (Cai, 2017) 
and the concept of embedded agency (Seo \& Creed, 2002) and applying it to analyse the development of a novel governance model at Southern University of Science and Technology (SUSTech). It asks the following research questions: How can the university governance model at SUSTech be considered innovation? If it is an innovation, how has it been implemented, through the actions of its initiators, in the highly institutionalised Chinese higher education system?

The rest of the paper is structured as follows. It starts with an introduction of SUSTech, clarifying why the university is an ideal case for our investigation. Next, we construct an analytical framework of our study. After explaining the research method, we present the findings of our empirical analysis in two sections in order to answer each of the two research questions. Finally, theoretical contributions and practical implications of the study are discussed in a conclusion.

\section{SUSTech as a miracle university}

Around the beginning of the millennium, Shenzhen, as the first economic zone and the most economically advanced city in China, saw the lack of strong research universities in the region as a threat to its continuing economic growth in a knowledge-based society (Liu $\&$ Cai, 2018). Hence, the Shenzhen municipal government decided to create the Southern University of Science and Technology (SUSTech) in March 2007 to establish a world-class research university to effectively strengthen local research and development (R\&D) capacity (Wang, 2011). SUSTech was officially established as a public university administrated by the Shenzhen Municipal Government in 2010. It was formally approved by China's Ministry of Education (MOE) in 2012 for piloting new paths of university development in China. As stated on the SUSTech website, the MOE agreed to build SUSTech as a testing ground to probe a modern higher education system with Chinese characteristics. While a brief history of SUSTech's development is depicted in Fig. 1, a few milestones are highlighted here:

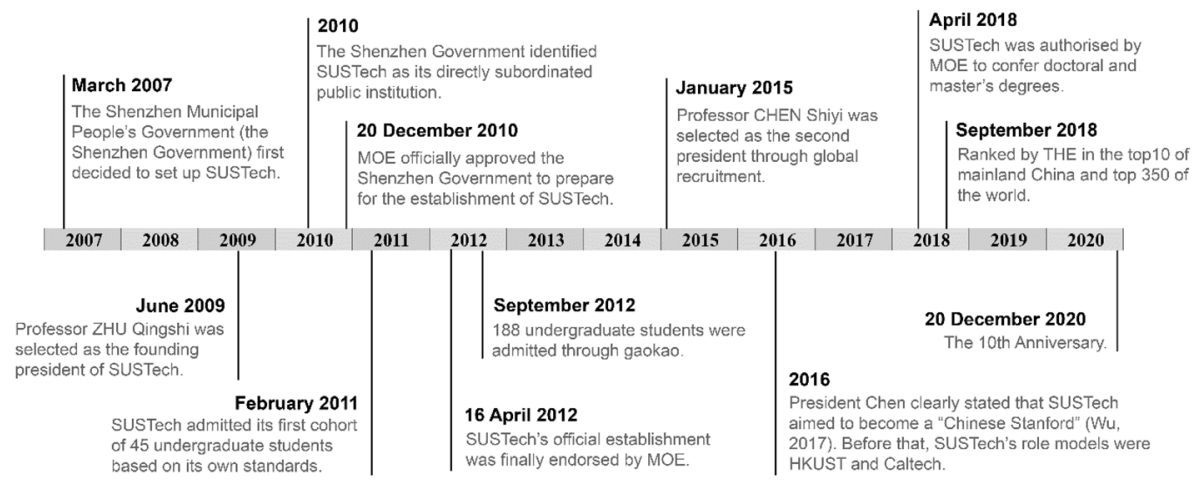

Fig. 1 The development history of SUSTech 
- In March 2007, a preparatory team for establishing SUSTech was convened by the Shenzhen municipal government. The team was led by the mayor and deputy mayor of the Shenzhen government and was composed of other government officials and representatives of other higher education institutions in the city.

- In June 2009, Professor Zhu Qingshi, the former president of the University of Science and Technology of China and a member of the Chinese Academy of Science, was selected as the founding President of SUSTech out of 200 candidates through global recruitment (Huang, 2012).

- In January 2014, Dr. Li Ming, the then deputy mayor of Shenzhen and a member of the Standing Committee of the Shenzhen Municipal Party Committee, was appointed as the second-term secretary of the Communist Party Committee (CPC) of SUSTech by the CPC of Shenzhen City, replacing Professor Zhu.

- In January 2015, Professor Chen Shiyi, who was vice president of Peking University and had 18-year work experience in American universities, was selected as the second president of SUSTech.

- In April 2018, SUSTech was authorised by the MOE to confer doctoral and master's degrees, signifying its research university status; it obtained this authorisation in the shortest time of all Chinese public universities (Mohrman et al., 2008).

- On 20th December 2020, SUSTech celebrated its 10th anniversary.

In news media, the quick rise of SUSTech in international university rankings has often been portrayed as a "miracle." Within 8 years after the establishment of the university, SUSTech was already among the top 10 universities in China, according to the Times Higher Education World University Ranking. We acknowledge that a university's ranking position is affected by various factors and that rankings can be criticised for their biased indicators. For instance, rich financial sources, as in the case for SUSTech, can greatly improve the indicators for better performance. We consider SUSTech a miracle university instead for its very brave and innovative actions that contrast to those of its counterparts in China.

Though the unique path and great achievements of SUSTech may be useful for envisioning a feasible model of a "university with Chinese characteristics", few studies have been published in English about the university. The available studies have primarily focused on analysing SUSTech's early endeavours to challenge the Gaokao (Chinese national college entrance examination) system by recruiting undergraduate students using its own admission criteria in 2011 (You \& Hu, 2013; Zha \& Hayhoe, 2014), though the university had to make a compromise with the MOE 1 year later (Wu, 2017; Zhang et al., 2012). Additionally, O'Sullivan (2018) reviewed students' participation in university governance, which is believed to be a major innovation in Chinese higher education. There has been a relatively large volume of literature in Chinese about SUSTech. The topics most closely related to our paper include the new student admission system (Chen et al., 2014; Cheng \& Sun, 2018; Li \& Ma, 2018) and its impact on the Gaokao reforms (You \& $\mathrm{Hu}, 2013)$, the relations between SUSTech and its administrative authority, the Shenzhen municipal government (Wang, 2012), the role of the university president in developing the university (Chen \& Fei, 2016; Kuang, 2012; Li, 2013; Wang, 2011) and comparison of the operation of SUSTech to the national legal framework (Wu, 2011). 
These studies in one way or another have implied that the most fundamental innovation at SUSTech is the creation of a unique university governance model. As Liu (2020, p. 287) stated, "university governance models often determine how universities balance their different purposes, and these can be affected by their located context." However, few studies have thoroughly investigated the initiation and implementation of a novel governance model at the university as a disruptive innovation that has fostered institutional changes in the highly institutionalised Chinese higher education system.

\section{Analytical framework building: embedded agency in the innovation process}

The analytical framework is constructed by integrating the insights of the conceptualisation of an innovation process in higher education (Cai, 2017) and the concept of embedded agency (Seo \& Creed, 2002). While the former provides an overarching framework for key components in an innovation process, the latter brings explanatory power for understanding how innovation initiators can leverage these factors.

\section{Embedded agency and innovation processes in higher education}

As mentioned earlier, Dancing in a cage can best characterise the reforms in Chinese public universities, as their actions are largely constrained by the system-level structure. Such a situation is very understandable from the perspective of new institutional theory (Meyer, 1977; Meyer \& Rowan, 1977), which highlights structuration and its constraints on the behaviour of organisations. DiMaggio and Powell (1983) also likened a social structure, i.e. the rationalist order, to an "iron cage." However, recent developments in institutional theory have criticised the views of new institutionalism for overstating the stability of organisational arrangements in a given organisational field and ignoring the roles of actors in institutional change (Cai \& Mehari, 2015). Recent studies in institutional analysis to a large extent respond to the "paradox of embedded agency" (Seo \& Creed, 2002): if the actions of organisational actors are constrained by takenfor-granted institutions, how and why can the actors induce institutional changes (Horton \& Wanderley, 2018)?

How universities can escape from the "cage" by breaking the institutionalised structure is a matter of organisational innovation, which often goes together with institutional innovation. Organisational innovation is defined as "any departure from the traditional practices of an organisation" (Levine, 1980). Institutional innovation can be generally understood as a process of institutional change, but "the change is a novel or unprecedented departure from the past" (Hargrave \& Ven, 2006).

In conceptualising an innovation process in higher education, Cai (2017) used nine attributes to understand the implementation of innovation as an institutionalisation process: (1) the problem to be addressed by innovation, (2) the aim of innovation, (3) the action of innovation, (4) the nature of innovation, (5) types of innovation, (6) stages of innovation, (7) the context of innovation, (8) the people involved in innovation and (9) the means of innovation. Institutionalisation is a process "by which social processes, 
obligations, or actualities, come to take on a rule-like status in social thought and action" (Meyer \& Rowan, 1977, p. 341). Furthermore, Cai (2017) identified three factors facilitating or impeding the institutionalisation of innovation, namely profitability, compatibility and agency:

- Profitability refers to tangible or intangible benefits that are perceived by either an organisation or its members as consequences of the innovation.

- Compatibility refers to the degree to which the norms, values and goals of innovation are congruent with the organisational environment or social context.

- Agency refers to the actions taken by some actors to change the existing institutional rules for facilitating innovation.

\section{Integrating the conceptualisation of innovation processes in higher education and embedded agency}

However, Cai (2017) did not elaborate on the relations between the three factors (profitability, compatibility and agency) in detail. We posit that the relations can be best captured through the lens of embedded agency (Seo \& Creed, 2002), as the nature of innovation concerns how actors, constrained by taken-for-granted rules, can induce institutional changes. In other words, the innovation process reflects interactions between structure and agency. The structure is institutional rules (DiMaggio \& Powell, 1983) and agency can be understood as "individuals' opportunities and actions in striving for their interests and goals" (Ursin et al., 2020, p. 312-313) through changing existing institutional rules.

To institutionalists, those actors performing agency roles are institutional entrepreneurs (Battilana et al., 2009; DiMaggio, 1988). Institutional entrepreneurship "reintroduces agency, interests and power into institutional analyses of organizations" (Garud et al., 2007, p. 957). The researchers in this camp share "the belief that actors have much greater leeway to interpret rules and enact institutional patterns and relationships than previously assumed in institutional theory" (Abdelnour et al., 2017, p. 1776). Institutional entrepreneurship is likely to take place in contexts with conflicting institutional arrangements (Leca et al., 2008), which are typically seen in innovation processes where institutional elements from the existing system co-exist with those induced by the innovation (Cai, 2017).

Strang \& Sine (2002) distinguished three types of institutional entrepreneurs: (1) states leading institutional reform movements from the top, (2) individual innovation initiators and (3) mobilised groups who push for new institutions that reflect their concerns and interests. As our research focused on innovation in the case university, only the actors in the last two categories fell within our analysis. For instance, when innovation initiators must strategically leverage different institutional templates to foster institutional change, they become institutional entrepreneurs. Meanwhile, organisational members involved in the innovation process can also contribute to institutional change if they perceive more benefits brought by the change. This is in line with DiMaggio's (1988, p. 14) claim: "new institutions arise when organized actors with sufficient resources see in them an opportunity to realize interests that they value highly".

\section{Analytical framework}

Based on the discussions above, the relationships between three factors (profitability, compatibility and agency) and their influences on the institutionalisation of innovation are depicted in Fig. 2. While the framework was developed to guide our empirical analysis, more concrete mechanisms 


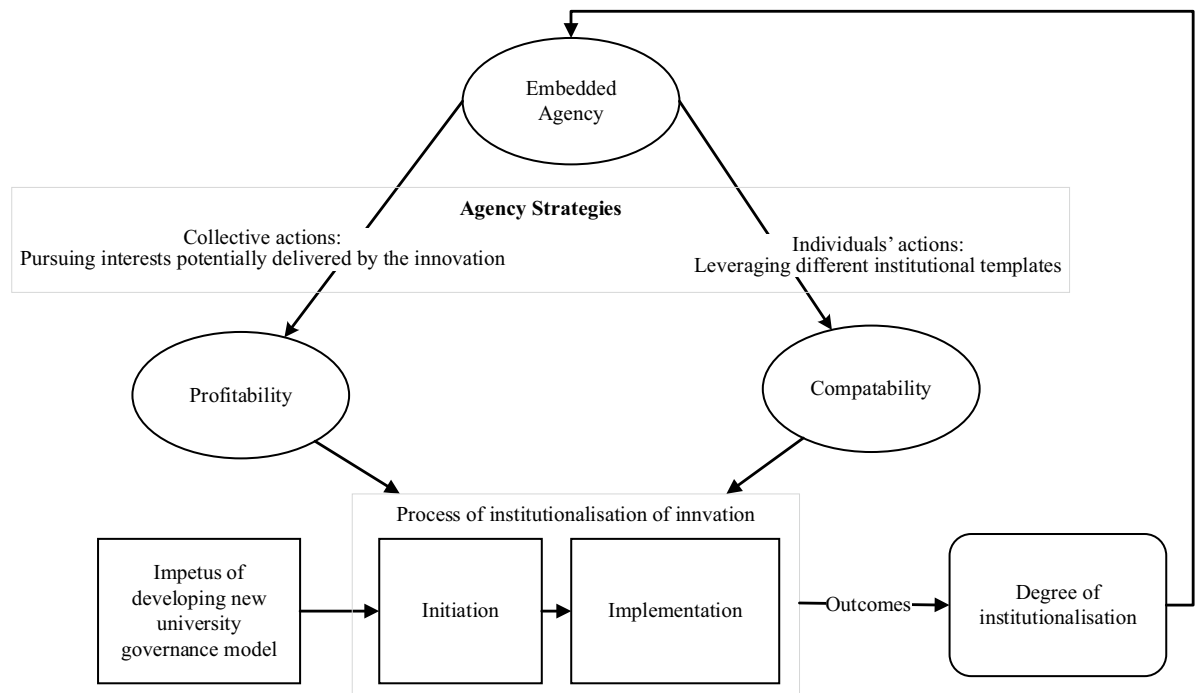

Fig. 2 Factors affecting the institutionalisation of innovation Source: Adapted from Cai (2017)

of embedded agency (or agency strategies) are expected to be discovered through our empirical investigation.

\section{Research method}

Our research design follows Creswell's (2014) suggestion that a qualitative research strategy is best suited to exploring an unknown phenomenon. In particular, we applied a qualitative case study method because it is a fitting methodology for understanding complex processes in their natural settings (Eisenhardt, 1989). Despite the exploratory nature of our research, it was not purely inductive research, which is typically seen in the grounded theory approach, using a "systematic set of procedures to develop an inductively derived grounded theory about a phenomenon" (Strauss \& Corbin, 1990). Rather, our case analysis was guided by an analytical framework (Fig. 2), following Yin's (1994) advice that "the use of theory... not only is an immense aid in defining the appropriate research design and data collection but also becomes the main vehicle for generalising the results of the ... study." (p. 32).

The case to be investigated was SUSTech. The data used in the case study were mainly obtained from eight semi-structured interviews carried out in November 2018 and August 2020. In addition, seven policy/regulation documents and six media reports (including journalists' interviews with the leaders of SUSTech) were used to supplement our first-hand empirical data. The data from various sources are described in Table 1.

The data were coded by using NVivo, a qualitative data analysis software, whereby we applied two complementary coding strategies. When analysing the key components in the innovation process at SUSTech, we were mainly guided by the analytical framework. When identifying agency strategies to cope with institutional incompatibility, we largely applied an open coding strategy, since the analytical framework did not provide mechanisms at the 
Table 1 Source of data

\begin{tabular}{|c|c|}
\hline \multicolumn{2}{|l|}{ List of interviewees } \\
\hline Interviewee 1 (I1) & Was a member of the initial preparation team for establishing SUSTech in 2007 \\
\hline $\mathrm{I} 2$ & Joined SUSTech and participated in preparation its establishment in 2010 \\
\hline I3 & Joined SUSTech as a university leader in 2014 \\
\hline I4 & $\begin{array}{l}\text { Was a member of the initial preparation team in 2007, is now a government } \\
\text { official of the Shenzhen Municipal Education Bureau }\end{array}$ \\
\hline I5 & Joined SUSTech as a faculty member in 2011 \\
\hline I6 & $\begin{array}{l}\text { Was a member of the initial preparation team in } 2007 \text {, is now a department head } \\
\text { of another higher education institution in Shenzhen }\end{array}$ \\
\hline I7 & $\begin{array}{l}\text { Took the lead in formulating the university charter in } 2015 \text {, is now a university } \\
\text { leader of another higher education institution in Shenzhen }\end{array}$ \\
\hline I8 & Joined SUSTech and participated in its preparation for establishment in 2010 \\
\hline \multicolumn{2}{|c|}{ List of policy documents and university regulations } \\
\hline Policy document 1 (D1) & $\begin{array}{l}\text { "Higher Education Law of the People's Republic of China", effective on January } \\
1,1999\end{array}$ \\
\hline D2 & $\begin{array}{l}\text { "Feasibility study report on the preparatory establishment of Southern University } \\
\text { of Science and Technology" ("Feasibility study report"), issued on August 22, } \\
2007\end{array}$ \\
\hline D3 & $\begin{array}{l}\text { "National outline for medium and long-term educational reform and development } \\
\text { (2010-2020)" ("2020 Blueprint"), promulgated by the MOE on July 29, } 2010\end{array}$ \\
\hline D4 & $\begin{array}{l}\text { "Notice of the Ministry of Education on approving the establishment of the } \\
\text { Southern University of Science and Technology," issued on December 20, } 2010\end{array}$ \\
\hline D5 & $\begin{array}{l}\text { "Interim measures for the management of Southern University of Science and } \\
\text { Technology" ("Interim Management Measures"), issued by the Shenzhen } \\
\text { municipal government on May 24, 2011, and effective on July 1, } 2011\end{array}$ \\
\hline D6 & $\begin{array}{l}\text { "Interim regulations on creating charters for higher education institutions," } \\
\text { approved by the MOE on July } 12,2011 \text {, and effective on January } 1,2012\end{array}$ \\
\hline D7 & $\begin{array}{l}\text { "Charter of Southern University of Science and Technology" ("University } \\
\text { Charter"), approved by the Education Department of Guangdong Province on } \\
\text { September } 28,2015\end{array}$ \\
\hline
\end{tabular}

List of media news and magazine interview reports

Media News (M1) S Stone, R. (2009). "University head Zhu Qingshi challenges old academic ways." Science, 326(5956), 1050

Stone, R. (2011). "Daring Experiment in Higher Education Opens Its Doors." Science, 332, 161

Zhou, Y \& Xing, S (2011) "Interim measures for the management of Southern University of Science and Technology" officially announced, Beijing News http://news.sciencenet.cn/htmlnews/2011/6/248236.shtm

Zhang, N., and Wang, S. (2014). "How can the reform of higher education be tested? - Interview with Zhu Qingshi, President of Southern University of Science and Technology." University (Academic Edition), 05, 4-17

He, H. (2014). "Wisdom and prudence, courage and responsibility — Interview with Academician Zhu Qingshi, President of Southern University of Science and Technology." Journal of Higher Education Management, 8(03), 1-6 
operational level. Following Creswell (2014)'s instruction on ensuring internal validity of qualitative data, we triangulated multiple sources of data, including interviews, documents and observations. Moreover, the data were coded by two authors, which helped avoid a biased integration of the data.

\section{Developing the university governance model at SUSTech as an innovation process}

In our case analysis, we identified five major innovations at SUSTech concerning the university governance model, the undergraduate student admission system, the residential college system, the personnel management system and the principal investigator system. The university governance model (Fig. 3) served as the hub and engine for other innovations at the university (I1,2,3 and 7, M4).

The novelty of the university governance model at SUSTech can be examined through the lens of Cai's (2017) nine attributes of an innovation process. The establishment of SUSTech, including developing its governance model, took place in the context in which Shenzhen was designated by the central government to experiment with new models of public administration and the Shenzhen municipal government had an urgent need to develop a top

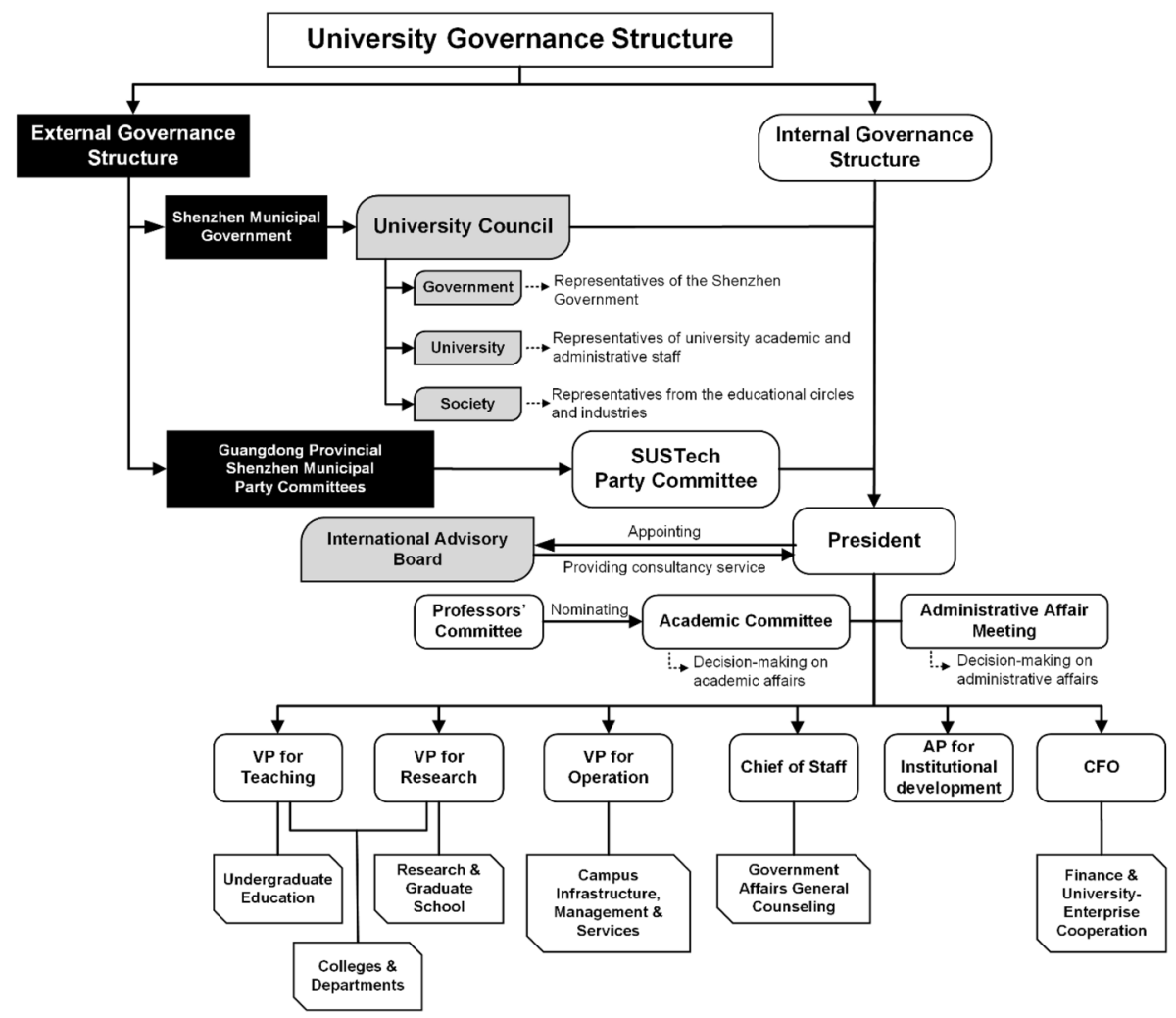

Fig. 3 The university governance structure of SUSTech. Source: Based on synthesising D5, D7, I1-3 and 7 
research university in the city to support its regional innovation and economic development (I1 and 2). The aim of developing a novel university governance model was two-fold. One was to explore a new way of managing modern universities in China (from the government's perspective) (D2), and the other was to secure the university's success by gaining a high level of autonomy (from the university's perspective) (D2, I1, 4, 6 and 7). However, one problem to be tackled was that the legislation and administration of Chinese universities provided them with little autonomy. Thus, SUSTech needed to be innovative in developing its university governance model. The type of innovation was both organisational and institutional. As the governance model greatly contrasted with existing practices in other Chinese public universities (I2, 3, 4 and 6) and even challenged legislation (D1), the nature of this innovation was disruptive. Specific innovative actions of the university governance model are described in Table 2. In the views of the interviewees, the governance model largely echoed common practices in the West (I1 and 2). The major means of implementing the governance model was through developing the Interim Management Measures and the University Charter and having them approved by the authorities (D5 and I7). Moreover, abundant financial resources were invested in the development of SUSTech (I3, 6 and 7). The people involved in the innovation included the members of the preparatory team for establishing SUSTech, the presidents and secretaries of the CPC (party secretaries) of SUSTech, university managers and faculty members (I1-8). The innovation process has gone through the following three periods.

1) Planning period (March 2007-May 2011), from the formation of the SUSTech preparatory team up to the Shenzhen municipal government's issue of the Interim Management Measures;

2) Legitimisation period (May 2011-September 2015), from the issuing of the Interim Management Measures up to the Guangdong provincial government's approval of the University Charter;

3) Implementation period, since the approval of the University Charter in September 2015.

According to the conceptualisation of the innovation process (Cai, 2017), compatibility and profitability are two major conditional factors affecting innovation implementation. Our case analysis revealed that the stakeholders and staff members of SUSTech perceived broad benefits from the novel university governance model. In the initial stage, the Shenzhen municipal government believed that a highly autonomous university, based on Western higher education models, would help build SUSTech into a world-class research university, which was urgently needed for the city's economic structural transformation (D2, I4, 6 and 7). In later periods, the autonomy gained has deepened other innovative actions at the university, particularly the principal investigator system, which has greatly contributed to the university's "miraculous" research performance. As one interviewee said in praise: "There is no university in Mainland China that allows us [the faculty members] to grow freely like SUSTech" (I5).

Our analysis showed that the challenges to university governance innovation mainly concerned institutional incompatibility. First, as depicted in Table 2, the primary incompatible element across the three periods of the innovation process concerned the university board as the highest decision-making body, as the Higher Education Law of China requests that "the presidents take overall responsibility under the leadership of the primary committees of the Communist Party of China" (D1). This was emphasised by our interviewees (I2, 3, 4 and 7). 


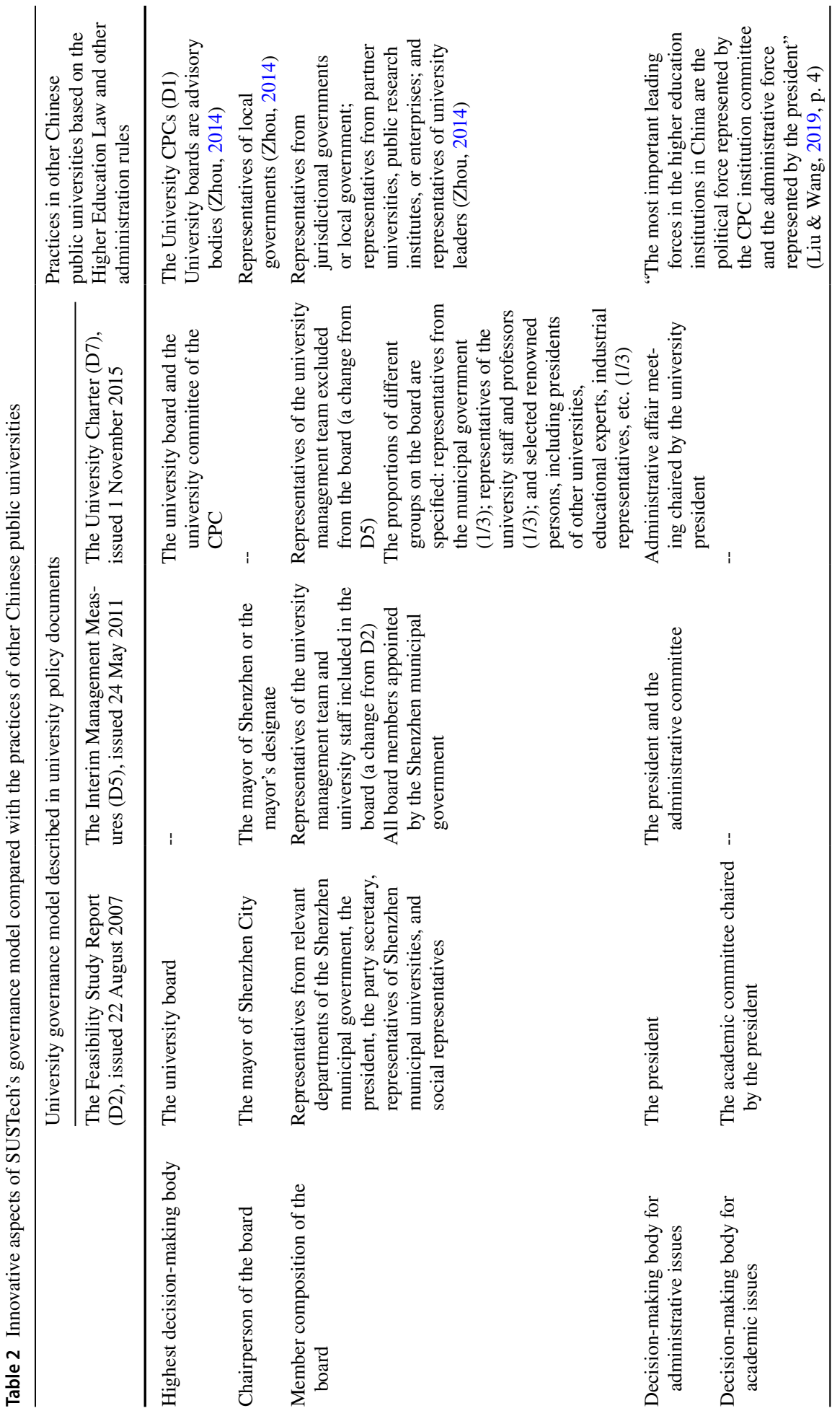




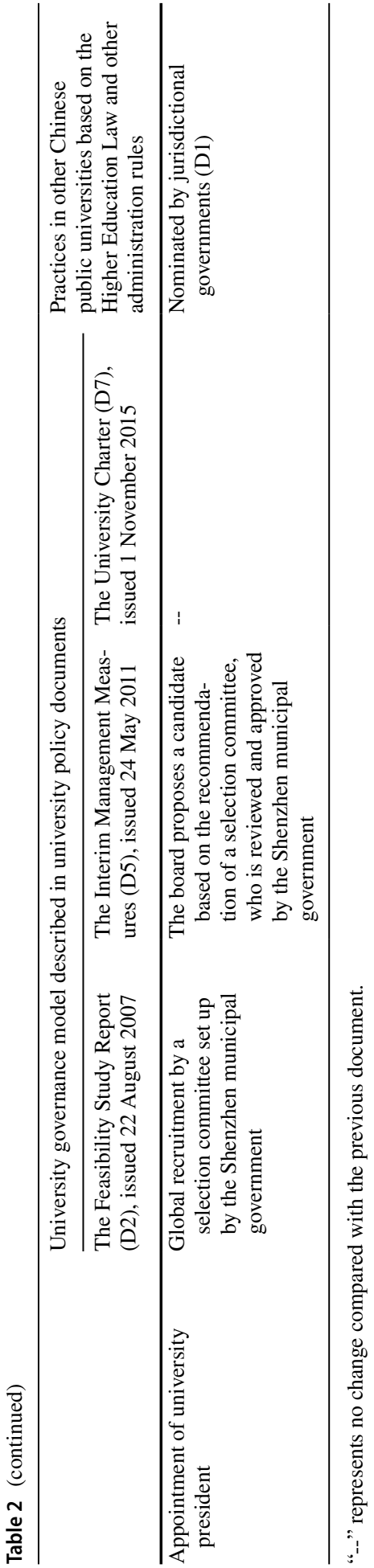


The second incompatible aspect was the contrast between the SUSTech model, in which the university president was proposed by the university board, and the practices in other public universities, where the presidents were directly nominated by jurisdictional governments (D1 and 2, I1, 2, 4 and 6). The third example of an institutionally incompatible element was that the academic committee of SUSTech made the final decision on academic issues, including disciplinary development and the hiring/promotion of academic staff, whereas in other public universities, these affairs were affected by multiple forces, primarily university administration (I2 and 5, D5). The academic autonomy enjoyed by SUSTech largely motivated the academic staff there. As a faculty member noted quite positively: "The academic committee system [of SUSTech] is pioneering in China. The 'big' professors [tenured full professors] make decisions on academic issues with no intervention from administrative power" (I5).

\section{Embedded agency: three agency strategies}

The role of agency is crucial in coping with the challenges of institutional incompatibility. In our analysis, we identified three strategies that innovation initiators/implementors as institutional entrepreneurs applied to mitigate challenges through leveraging different institutional templates (or legitimised rules of the game). We named the three strategies using the metaphors: new wine in a new bottle, new wine in an old bottle and old wine in a new bottle. The 'wine' refers to actions (either planned or implemented) and the 'bottle' refers to an institutional template. As such, these strategies can be put into a two-dimension typology (Fig. 4). These strategies aimed to legitimise innovation, hence mitigating the challenges of institutional incompatibility. We found that three factors were vital in implementing the strategies, namely, (1) the vision of innovation initiators, (2) their skill at playing the power

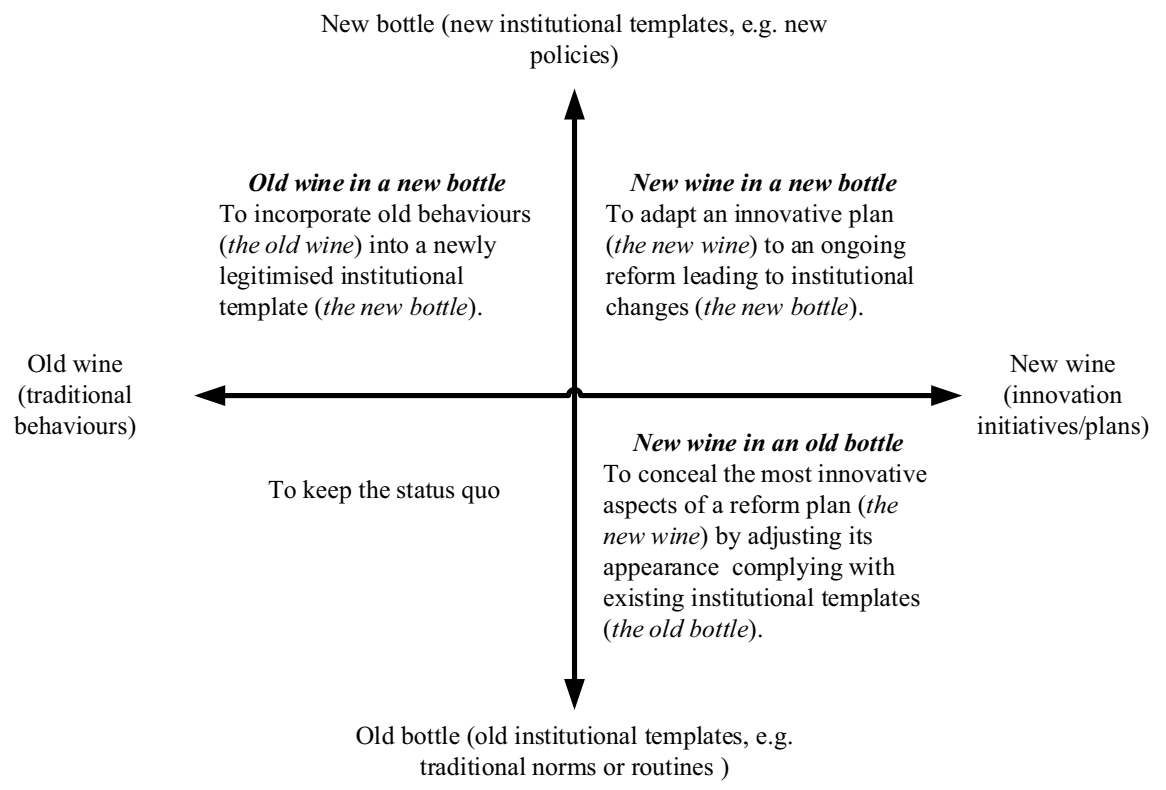

Fig. 4 Typology of agency strategies 
game and (3) the social capital of these institutional entrepreneurs. Below, we provide three examples, based on our data analysis, to demonstrate how each strategy was used to mitigate institutional challenges in the innovation process.

\section{New wine in a new bottle}

In the planning period (March 2007-May 2011), the innovation plan (the new wine) was to establish the university board as the highest decision-making body in matters including the appointment of the university president (I2, 4, 7, D1 and 5). As this was against the common practice in Chinese higher education, in which university boards played an advisory role and university presidents were appointed by the government, SUSTech encountered a severe challenge in implementing this plan. To mitigate the challenge, the preparation team for establishing SUSTech and President Zhu, who took leadership responsibility from the team after being appointed as the founding president, tried to convince the municipal government to integrate the innovation of SUSTech as part of an on-going reform-Shenzhen as a pilot city for exploring new models of public administration in regional governments (I2 and 6). President Zhu also grasped another opportunity when he saw that one aim of the Outline of China's National Plan for Medium and Long-term Education Reform and Development (2010-2020) was to explore a modern university model with Chinese characteristics. Both these reforms (the new bottle) were used to legitimise SUSTech's unprecedented innovation initiatives (D3, M5 and I2).

The implementation of the new wine in a new bottle strategy reflected President Zhu's great vision and skills in the power game. With his experience as a Chinese university leader and a researcher at Western universities (e.g. the University of Oxford, the University of Cambridge and the Massachusetts Institute of Technology), President Zhu shared a clear view with his colleagues that SUSTech could only be successful through gaining great autonomy (M4). To maximise his influence over decision-making, he also asked to be appointed the university's party secretary when negotiating his appointment as SUSTech's founding president with the Shenzhen government (M1 and 2). Although this sounded impossible, Zhu understood that the Shenzhen government had high expectations for his presidency and thus his request would possibly be accepted (I3, 4 and 7). Eventually, it was. Meanwhile, he compromised with the Shenzhen government by agreeing that the mayor of Shenzhen should chair the university board and that half the representatives from the Shenzhen government should sit on the board (D5, I1 and 7). Along with the power game, President Zhu emphasised that SUSTech's new governance model, characterised by a high level of institutional autonomy, was fundamental to the university (D3, M3, I 2, 5, 6 and 8).

\section{New wine in an old bottle}

After the reform plan was sanctioned by the Shenzhen municipal government in May 2011, the next challenge was to modify it to make the University Charter, as an official university policy document to be approved by provincial authorities (D7 and I7). As mentioned earlier, the university board and presidential appointment system at SUSTech were strong deviations from the Chinese higher education tradition. To avoid an immediate rejection by the authorities, the innovation initiators tried to conceal the most innovative aspect of their reform plan (the new wine) by letting it appear compliant with 
existing regulations in Chinese higher education, such as the dual leadership system consisting of both university president and party secretary (the old bottle). Despite the compromise, the university board remained the primary decision-making body in the approved University Charter (I1, 3, 7 and 8, D7). Although the university board does not directly appoint the president, it can propose a candidate to the government for formal nomination. This was considered a great success of the university. As stressed by I2, "SUSTech is the only public university in China having a university board system equivalent to its Western counterpart".

The implementation of the new wine in an old bottle strategy was largely attributed to Dr. Li Ming, who was appointed by the Shenzhen Municipal Party Committee in January 2014 to succeed Professor Zhu as the second-term Party Secretary of SUSTech. As the former Deputy Mayor of Shenzhen, Dr. Li's vision and social capital were essential to the innovation process. With Dr. Li's support for the inclusion of the innovative governance model in the University Charter, the charter drafting team was able to retain principal elements, such as "the university board as the primary decision-making body" (I3 and 7) in the charter, despite opposition from some university managers who were appointed by the Shenzhen municipal government (I4, 7 and 8, D7). Even when the provincial authorities expressed their negative views on the proposed Charter, Dr. Li eventually managed to persuade the decision-makers to approve the charter by using his social networks in governments.

\section{Old wine in a new bottle}

After the university board system at SUSTech was officially approved, it became a newly legitimised institutional template (a new bottle). However, around that time, China started a movement towards tighter control of universities (I2 and 8). More managers with a government background were transferred to the university, and they tended to push decision-making power from the university board back to the Shenzhen municipal government (I1, 2 and 7). Meanwhile, the established CPC at the university tried to gain more influence (I3, 7 and 8). Tensions between the university president, the Shenzhen municipal government and the Party Committee became a challenge in implementing the university's governance model (I1-4 and 7). To mitigate this challenge, innovation initiators at SUSTech tried to incorporate the control by the local government and the university's CPC (the old wine), into the university's board system.

The main actor behind this implementation of the old wine in a new bottle strategy was Professor Chen Shiyi, who was appointed as the second-term University President in January 2015. He skilfully played a hard power game. In the university board, the university president, as a standing member of the board, was in a less powerful position compared with the city mayor and the university party secretary, who were the chair and deputy chair of the board respectively (I1 and I2). However, the president exerted his influence over university management through administrative affair meetings, which were chaired by the president weekly for making decisions on major teaching, research and administrative affairs. Because the university board normally convened meetings twice per year, most decisions on the university's major affairs were made at administrative affairs meetings (I7 and 8, D7). Moreover, President Chen was aware that the university's faculty members were enjoying great benefits resulting from the new governance model 
and thereby tried to engage them (as institutional entrepreneurs) in protecting the university's autonomy (I5 and 8).

\section{Conclusions}

Our study explored the development of the governance model at SUSTech through a theoretical lens integrating the insights of embedded agency and the conceptualisation of innovation processes in higher education. Although the model, i.e. the university board as the highest decision-making body, is not new in Western higher education, it is novel in the Chinese context. Chinese public universities' endeavours towards institutional autonomy have been constrained by the system-level structure that is connected to the government's tight control (Han \& Xu, 2019). This phenomenon was described by Yang et al. (2007) as "dancing in a cage". In our analytical lens, the pain of dancing in a cage lies in institutional incompatibility, meaning that the norms and goals of reforms/innovation are not congruent with the institutional contexts of Chinese higher education. However, our study showed that SUSTech demonstrated a rare example of escaping from the bondage: The original goal of the innovation, namely high university autonomy, had been largely achieved regardless of some comprises. The institutional incompatibility was mitigated through several agency strategies. The innovation initiators' visions, skills in playing power games and social capital are vital for implementing the strategies.

Besides its empirical value, our paper makes three theoretical contributes to the literature. First, it opens new horizons for resolving a long-standing dilemma in China's endeavour to develop modern universities by preserving the Chinese essence while adopting Western means. Second, it advances the discussions concerning the "paradox of embedded agency" in the context of innovations in higher education by suggesting three agency strategies, labelled using the metaphors of new wine in a new bottle, new wine in an old bottle and old wine in a new bottle. Third, it develops an analytical framework for managing university innovations focusing on the role of embedded agency, which is likely to be applicable in empirical settings outside Chinese higher education.

We also acknowledge some limitations of our research. For instance, due to SUSTech's unique features as a science and technology university established from scratch with abundant financial resources and $90 \%$ of faculty members with work/study experience abroad, the experience of the case university might not be generalisable to other Chinese public universities. Moreover, while the literature has revealed that Chinese universities are subject to three influences, namely state control, the Confucian tradition and western models (Jiang \& Mok, 2019; Li \& Zhu, 2019; Zha et al., 2016), our case analysis mainly highlighted the tensions between the Chinese statist system and the influences of Western models. Our empirical data did not lead us to investigate how Western practicality can fuse with Confucian virtues - an issue Yang (2014) stressed. Marginson (2011) considered that Confucianism plays an important role in shaping higher education systems in, for example, Japan, Korea, China and Singapore. The absence of the cultural dimension in our analysis might again be due to case specificity.

Our paper was finalised as SUSTech was celebrating its 10th anniversary in a series of events, where the high performance of organisational innovations at the university was praised as fundamental to the success of SUSTech. Thus, SUSTech will be committed to further developing its identity as an innovative Chinese public university. As China is 
continuously transforming its higher education into an educational system with Chinese characteristics, SUSTech will be both an interesting case for deeper research and a testbed for experimenting with new models of universities with Chinese characteristics. One positive scenario could be that the best practices of SUSTech may be legitimised as a new institutional template to guide future university reforms in the country.

Funding This work was supported by the General Project for Education, The National Social Science Fund of China, "Societal Impact and Assessment Mechanism of International (Regional) Scientific Research Cooperation in Chinese Universities", Grant number: BIA190166.

Open Access This article is licensed under a Creative Commons Attribution 4.0 International License, which permits use, sharing, adaptation, distribution and reproduction in any medium or format, as long as you give appropriate credit to the original author(s) and the source, provide a link to the Creative Commons licence, and indicate if changes were made. The images or other third party material in this article are included in the article's Creative Commons licence, unless indicated otherwise in a credit line to the material. If material is not included in the article's Creative Commons licence and your intended use is not permitted by statutory regulation or exceeds the permitted use, you will need to obtain permission directly from the copyright holder. To view a copy of this licence, visit http://creativecommons.org/licenses/by/4.0/.

\section{References}

Abdelnour, S., Hasselbladh, H., \& Kallinikos, J. (2017). Agency and institutions in organization studies. Organization Studies, 38(12), 1775-1792.

Battilana, J., Leca, B., \& Boxenbaum, E. (2009). How actors change institutions: Towards a theory of institutional entrepreneurship. The Academy of Management Annals, 3(1), 65-107.

Cai, Y. (2012). Traditional reform philosophy and challenges of higher education reforms in China. International Journal of Humanities and Social Science, 2(6), 60-69.

Cai, Y. (2017). From an analytical framework for understanding the innovation process in higher education to an emerging research field of innovations in higher education. Review of Higher Education, 40(4), $585-616$.

Cai, Y., \& Mehari, J. (2015). The use of institutional theory in higher education research. In J. Huisman \& M. Tight (Eds.), Theory and Method in Higher Education Research Iii (pp. 1-25). Emerald: Bingley.

Cai, Y., \& Yan, F. (2020). Developing Chinese higher education in tensions, a conclusion. In M. A. Peters (Ed.), Encyclopedia of Educational Philosophy and Theory (pp. 1-6). Springer Singapore: Singapore.

Chen, A., Gao, W., \& Yue, L. (2014). Comparison of independent enrollment reform paths between Southern University of Science and Technology and Shanghai University of Science and Technology: A case study from the perspective of organizational reform (in Chinese). Journal of Higher Education Management, $8(05), 73-78$.

Chen, J., \& Fei, R. (2016). Revisiting the de-administration of colleges and universities_— Taking Southern University of Science and Technology as an example (in Chinese). Modern Economic Information, 15, $29-30$.

Cheng, C., \& Sun, B. (2018). Southern University of Science and Technology's 631 enrollment model and the selection of innovative talents (in Chinese). Educational Modernization, 5(03), 26-27.

Creswell, J. W. (2014). Research design: Qualitative, quantitative, and mixed methods approaches. Los Angeles, London, New Delhi, Singapore: SAGE Publications.

DiMaggio, P. J. (1988). Interest and agency in institutional theory. In L. G. Zucker (Ed.), Institutional Patterns and Organizations: Culture and Environment (pp. 3-21). Cambridge, MA: Ballinger.

DiMaggio, P. J., \& Powell, W. (1983). The Iron Cage Revisited: institutional isomorphism and collective rationality. American Sociological Review, 42(2), 147-160.

Du, X. (2019). Critical thinking and ideology in Chinese higher education. International Higher Education, 97, 15-17.

Eisenhardt, K. M. (1989). Building theories from case study research. The Academy of Management Review, 14(4), 532-550.

Garud, R., Hardy, C., \& Maguire, S. (2007). "Institutional Entrepreneurship as Embedded Agency: An Introduction to the Special Issue." Organization Studies, 28(7), 957-969. 
Han, S., \& Xu, X. (2019). How far has the state 'stepped back': An exploratory study of the changing governance of higher education in China (1978-2018). Higher Education, 78(5), 931-946.

Hargrave, T. J., \& Ven, A. H. V. D. (2006). A collective action model of institutional innovation. Academy of Management Review, 31(4), 864-888.

Hayhoe, R. (1996). China's Universities 1895-1995: A century of cultural conflict. Hong Kong: Comparative Education Research Centre.

Horton, K. E., \& Wanderleyd. A. , C. (2018). Identity conflict and the paradox of embedded agency in the management accounting profession: Adding a new piece to the theoretical jigsaw. Management Accounting Research, 38, 39-50.

Huang, B. (2012). "Inspirations from the Southwest United University to the Reform of Higher EducationAlso on the Exploration of Southern University of Science and Technology (in Chinese)." HigherEducation Development and Evaluation, 28(02), 43-48 + 118.

Jiang, J., \& Mok, K. H. (2019). asserting global leadership in higher education: Governance with strong government in China. In D. S. L. Jarvis \& K. H. Mok (Eds.), Transformations in Higher Education Governance in Asia: Policy, Politics and Progress (pp. 101-121). Singapore: Springer.

Kuang, M. (2012). "Research on De-Administration of University Organization Structure —— the Case Study of Southern University of Science and Technology (in Chinese)." Higher Education and Economy, $25(01), 26-30+60$.

Leca, B., Battilana, J., \& Boxenbaum, E. (2008). "Agency and Institutions: A Review of Institutional Entrepreneurship." Harvard Business School Working Papers, 08-96, 1-52.

Levine, A. (1980). Why Innovation Fails. Albany: State University of New York Press.

Li, B., \& Ma, D. (2018). A review of "631" comprehensive evaluation admission model-A case study of South University of Science and Technology of China (in Chinese). Shanghai Educational Evaluation Research, 7(02), 50-54.

Li,J.,\&Zhu,X.(2019).Conceptualizing and Contextualizing HigherEducation with Chinese Characteristics: Ontological and Epistemological Dimensions: Springer Singapore.

Li, P. (2013). A probe into the Modern University System of Southern University of Science and Technology (in Chinese). Special Zone Practice and Theory, 04, 61-65.

Liu, B., \& Wang, X. (2019). Governance and Management in Chinese Higher Education Institutions. In M. A. Peters (Ed.), Encyclopedia of Educational Philosophy and Theory (pp. 1-8). Springer Singapore: Singapore.

Liu, C., \& Cai, Y. (2018). Triple helix model and institutional logics in Shenzhen Special Economic Zone. Science and Public Policy, 45(2), 221-231.

Liu, X. (2020). Institutional governance in the development of private universities in China. Higher Education, 79(2), 275-290.

Marginson, S. (2011). Higher education in East Asia and Singapore: Rise of the Confucian model. Higher Education, 61(5), 587-611.

Meyer, J. W. (1977). The effects of education as an institution. American Journal of Sociology, 83(1), 53-77.

Meyer, J. W., \& Rowan, B. (1977). Institutionalized organizations: Formal structure as myths and ceremony. American Journal of Sociology, 83(2), 340-363.

Mohrman, K., Ma, W., \& Baker, D. (2008). The Research University in transition: The emerging global model. Higher Education Policy, 21(1), 5-27.

Mok, K. H., \& Han, X. (2017). Higher education governance and policy in China: Managing decentralization and transnationalism. Policy and Society, 36(1), 34-48.

O’Sullivan, K. (2018). " Working Together to Foster Education Innovation: The Student Dimension in University Governance." IOSR Journal Of Humanities And Social Science (IOSR-JHSS), 23(2), 59-66.

Seo, M., \& Creed, D. W. E. (2002). Institutional contradictions, praxis and institutional change: A dialectical perspective. Academy of Management Review, 27(2), 222-247.

Strang, D., \& Sine, W. (2002). Interorganizational Institutions. In J. A. C. Baum (Ed.), Companion to Organizations (pp. 497-519). Malden, MA: Blackwell.

Strauss, A. L., \& Corbin, J. M. (1990). Basics of qualitative research: Grounded theory procedures and techniques. Newbury Park, Calif.: Sage Publications.

Ursin, J., Vähäsantanen, K., McAlpine, L., \& Hökkä, P. (2020). Emotionally loaded identity and agency in Finnish Academic Work. Journal of Further and Higher Education, 44(3), 311-325.

Wang, C. (2012). The relationship between government and university in the view of power-The case of Southern University of Science and Technology (in Chinese). Fudan Education Forum, 10(03), 61-65. 
Wang, H. (2011). Southern University of Science and Technology: An experiment of modern university model-Speaking fromZhu Qingshi as the President of Southern University of Science and Technology (in Chinese). Journal of Higher Education Management, 5(05), 29-34.

Wu, H. (2017). New "Startups" in a rigid higher education system: China's Young Elite Institutions. International Higher Education, 91, 32-34.

Wu, Y. (2011). "Legal Institutions of Higher Education: Review of the "Interim Measures for the Management of Southern University of Science and Technology" (in Chinese)." University (Academic Edition), $11,30-35+16$.

$\mathrm{Xu}, \mathrm{S}$. (2005). Impacts of globalisation on higher education reform in China: A trend of decentralisation and autonomy. Educational Research for Policy and Practice, 4(2), 83-95.

Yan, F., \& Cai, Y. (2019). Modernization of higher education in China, an introduction. In M. A. Peters (Ed.), Encyclopedia of Educational Philosophy and Theory (pp. 1-4). Springer Singapore: Singapore.

Yang, R. (2014). Western practicality fused with Confucian virtues: How far can it take East Asia's higher education? Keynote speech at HERDSA (The Higher Education Research and Development Society of Australasia) Annual International Conference 2014, Hong Kong Baptist University, July 10.

Yang, R. (2017). The cultural mission of China's elite universities: Examples from Peking and Tsinghua. Studies in Higher Education, 42(10), 1825-1838.

Yang, R., Vidovich, L., \& Currie, J. (2007). "Dancing in a cage": Changing autonomy in Chinese higher education. Higher Education, 54(4), 575-592.

Yin, R. K. (1994). Case study research: Design and methods. Thousand Oaks: SAGE Publications.

You, Z., \& Hu, Y. (2013). Walking a policy tightrope: The dilemma of balancing diversification and equality in Chinese College Entrance Examination Reform. Higher Education Policy, 26(3), 309-324.

Zha, Q., \& Hayhoe, R. (2014). The "Beijing Consensus" and the Chinese Model of University Autonomy. Frontiers of Education in China, 9(1), 42-62.

Zha, Q., \& Shen, W. (2018). The paradox of academic freedom in the Chinese context. History of Education Quarterly, 58(3), 447-452.

Zha, Q., Shi, J., \& Wang, X. (2016). Is there an alternative university model? The debate around the Chinese Model of the University. In J. E. Cote \& A. Furlong (Eds.), Routledge Handbook of the Sociology of Higher Education (pp. 273-285). New York: Routledge.

Zhang, G., Zhao, Y., \& Lei, J. (2012). Between a rock and a hard place: Higher education reform and innovation in China. On the Horizon, 20(4), 263-273.

Zhou, G. (2014). Modernization of higher education governance in China: Current situation, problems and countermeasures (in Chinese). China Higher Education Research, 09, 16-25.

Zhu, X., \& Li, J. (2018). Conceptualizing the ontology of higher education with Chinese characteristics. Educational Philosophy and Theory, 50(12), 1144-1156.

Publisher's Note Springer Nature remains neutral with regard to jurisdictional claims in published maps and institutional affiliations. 